\section{$\underset{\substack{\text { hommes } \\ \text { \& migrations }}}{ }$}

\section{Hommes \& migrations}

Revue française de référence sur les dynamiques

migratoires

$1309 \mid 2015$

Le $3 e$ âge des migrants

\title{
The Good Lie
}

Film américain de Philippe Falardeau

\section{Anaïs Vincent}

\section{OpenEdition \\ 1 Journals}

\section{Édition électronique}

URL : http://journals.openedition.org/hommesmigrations/3123

DOI : 10.4000/hommesmigrations.3123

ISSN : 2262-3353

\section{Éditeur}

Musée national de l'histoire de l'immigration

\section{Édition imprimée}

Date de publication : 1 janvier 2015

Pagination : 199-200

ISBN : 978-2-919040-30-8

ISSN : $1142-852 X$

Référence électronique

Anaïs Vincent, «The Good Lie », Hommes \& migrations [En ligne], 1309 | 2015, mis en ligne le 31 août 2015, consulté le 24 septembre 2020. URL : http://journals.openedition.org/hommesmigrations/3123 ; DOI : https://doi.org/10.4000/hommesmigrations.3123

Ce document a été généré automatiquement le 24 septembre 2020.

Tous droits réservés 


\title{
The Good Lie
}

\author{
Film américain de Philippe Falardeau
}

\section{Anaïs Vincent}

1 Récompensé par le prix du jury au Festival du film américain de Deauville, The Good Lie est le premier long-métrage hollywoodien du réalisateur québécois Philippe Falardeau (Monsieur Lahzar). D’ores et déjà disponible en téléchargement sur iTunes, il est sorti en France dernièrement.

2 Diplômé en sciences politiques à l'université d'Ottawa, expert en relations internationales, le cinéaste raconte dans The Good Lie l'histoire vraie des lost boys, ces 20000 enfants des ethnies nuer et dinka qui ont fui la guerre civile en 1980 au Soudan. Mamere (Arnold Oceng), Abital (Kuoth Wiel), Jeremiah (Ger Duany), Paul (Emmanuel Jal) sont quatre d'entre eux. La vie paisible de leur village est brutalement interrompue par la barbarie des massacres. Les trois garçons fuient, accompagnés de leur sœur Abital, pour une longue et terrible marche de 1000 kilomètres en direction du camp de Kakuma au nord-ouest du Kenya. Ils réussissent à survivre et atteignent leur destination.

Dix années se sont écoulées. Les protagonistes, toujours réfugiés dans ce camp, s'apprêtent à partir bientôt s'installer aux États-Unis. Leurs noms figurent enfin sur la liste des heureux élus. Abital part à Boston, alors que ses frères s'envolent pour Kansas City. Carrie Davies (Reese Witherspoon), une employée d'une association caritative gouvernementale, les accueille et les accompagne dans leur découverte de la société américaine, jusqu'à ce qu'un “juste mensonge” renverse l'équilibre familial.

4 La question de l'exil est au cœur du récit, comme dans le documentaire de Magan Mylan, A Great Wonder : Lost Children of Sudan (2000). On retrouve les mêmes étapes et les mêmes heurts. Arrivés sur place, les réfugiés sont confrontés au monde du travail, à l'incivilité et à l'absurdité du capitalisme. Entre désillusions et fascination pour la culture américaine, ils se battent pour s'adapter et survivre dans cet environnement qu'ils ne comprennent pas. Avec un académisme certain, Philippe Falardeau parvient avec aisance à nous émouvoir en usant des recettes de l'industrie cinématographique des blockbusters américains. Mais nulle surprise, nulle audace. 
5 Ce long-métrage repose avant tout sur la direction des acteurs et la qualité de leur interprétation. D'origine soudanaise et éthiopienne, ils ont vécu eux-mêmes l'horreur de la guerre, la vie de réfugié et le déracinement. Deux d'entre eux (Emmanuel Jal et Ger Duany) ont été enfants soldats. Ils ont donc mis leur expérience à profit et expliquent comment le tournage à parfois pu être très dur émotionnellement. Quant à Reese Whiterspoon, elle incarne son rôle avec justesse. Pour la préparation, elle est allée visiter des camps de réfugiés pour se confronter directement à la réalité et ne pas la fantasmer.

6 Cette production hollywoodienne un peu manichéenne dresse un tableau flatteur de l'action humanitaire américaine. Carrie Davies va tout mettre en œuvre pour aider cette famille dans un élan d'humanisme remarquable, avec l'appui de sa hiérarchie et une administration finalement plutôt conciliante. Le retournement du scénario estompe heureusement cette impression.

7 Ce long-métrage ,0avec son lot de clichés, a le mérite d'alerter les consciences sur la situation désastreuse de ces populations et de souligner la responsabilité de l'aide internationale face à ces drames. 